\title{
High-Temperature Stable Electrodes for Langasite Based Surface Acoustic Wave Devices
}

\author{
Richter, Denny and Fritze, Holger \\ Clausthal University of Technology \\ Institute of Energy Research and Physical Technologies \\ Am Stollen 19 \\ 38640 Goslar \\ Germany
}

\section{Introduction}

Piezoelectric single crystals like langasite, langatate or gallium orthophosphate enable the development of high-temperature stable devices for sensor applications in harsh environments, like in combustion systems, high-temperature fuel cells or gas turbines. The development of wireless surface acoustic wave sensors that can be operated long-term at about $650{ }^{\circ} \mathrm{C}$ for process monitoring or in the time scale of several hours at temperatures of up to $950{ }^{\circ} \mathrm{C}$ for testing purposes is the goal of the SAWHOT project.

Although e.g. langasite shows piezoelectric behaviour up to its melting point at $1470{ }^{\circ} \mathrm{C}$ [1], the hightemperature operation of piezoelectric devices is limited by the stability of electrode materials and packaging. While the stability of metal electrodes on bulk acoustic wave (BAW) resonators can be ensured by deposition of platinum thick films (e.g. $3 \mu \mathrm{m}$ ), the electrodes on surface acoustic wave (SAW) resonators should not exceed a thickness of $100 \mathrm{~nm}$ due to the influence of the electrode mass on the acoustic waves. In this work, potentially suited materials and materials systems are investigated with respect to their applicability for langasite based SAW devices at high temperatures. The electrodes should remain stable under harsh conditions while exhibiting a good adhesion on langasite as well as a high conductivity.

\section{State of the Art}

Noble metals, like platinum, rhodium, palladium or iridium are, in general, suited for high-temperature application due to their high melting point and their oxidation resistance. Nevertheless, there are some restrictions and conditions, that decrease the applicability of pure metal as thin film electrodes with a thickness around $100 \mathrm{~nm}$ at temperatures higher than $600{ }^{\circ} \mathrm{C}$

In general, thin films of noble metals show only a poor adhesion on surfaces of oxide substrates like langasite. Therefore, an intermediate adhesion layer of a less noble metal has to be used to improve the adhesion of the electrode on the substrate by forming a transition layer between oxide and metal [1]. Commonly used adhesion layers for high-temperature electrodes based on noble metals are titanium, tantalum or zirconium [2,3]. The optimal thickness of the adhesion layer is about $10 \mathrm{~nm}$. Thicker adhesion layers may decrease the stability of the electrode significantly [4]. Also, the potential formation of alloys and eutectics of adhesion layer material, substrate and electrode materials have to be suppressed, to ensure a long-term stability of the layer structure.

Three major failure mechanisms, i.e. evaporation, oxidation and agglomeration, can result in the destruction of electrodes consisting of the above-mentioned noble metals. Due to the high vapour pressure of these metals, their direct evaporation has only a minor influence on the stability [5]. However, in oxygen containing atmospheres the evaporation of volatile oxides in oxygen containing atmospheres at elevated temperatures can exceed the metal loss in inert atmospheres by several orders of magnitude.

Beside the evaporation of volatile oxides, agglomeration is an important process decreasing the high temperature stability of metal electrodes. Agglomeration is observed for many metal thin films with high surface to volume ratio at elevated temperatures [6]. The agglomeration process is caused by a high surface tension of the film and low bonding energies between the thin film and the substrate [7]. The agglomeration process is driven by the tendency of the metals to shift their lattice parameters to the bulk values and to decrease the strain induced by the substrate.

The surrounding atmosphere can influence the agglomeration process, too. The formation of agglomerates in gold thin films can for example be reduced in oxygen containing atmospheres [7], while the presence of oxygen increases the coalescence process in platinum films [2]. The agglomeration can be shifted to higher temperatures by increasing the thickness of the metal films. Gadkari et al. performed measurements with metal films of different thickness. While platinum films with a thickness of $50 \mathrm{~nm}$ showed 
first agglomerations already at $620^{\circ} \mathrm{C}$, the formation of agglomerates of $100 \mathrm{~nm}$ thick films is not visible up to $780^{\circ} \mathrm{C}[8]$.

The coalescence process can be reduced by application of thin protection layers of oxide materials [9] like $\mathrm{SiO}_{2}$ [8] or $\mathrm{Al}_{2} \mathrm{O}_{3}$ [4], which are high-temperature stable. They also exhibit a low conductivity at elevated temperatures, which is important if the film is applied on the whole surface of the device and not only on the electrodes. Films with a thickness of only $10 \mathrm{~nm}$ already result in a significant improvement of the high temperature stability.

Promising alternatives to metal electrodes are conductive ceramic electrodes, which may offer a good long-term stability at high temperatures. Common materials already used as cathode layers in hightemperature solid oxide fuel cells are for example LSM $\left(\mathrm{La}_{0.65} \mathrm{Sr}_{0.35} \mathrm{MnO}_{3}\right)$ and LSCF $\left(\mathrm{La}_{0.6} \mathrm{Sr}_{0.4} \mathrm{Co}_{0.2} \mathrm{Fe}_{0.8} \mathrm{O}_{3}\right)$ [10]. Especially LSM shows comparably high conductivities without large decreases even at lower temperatures and is therefore be considered as potential electrode material. General disadvantages of this material group compared to metal electrodes are the lower conductivity of the materials in the low-temperature range. Further, problems may be caused by changes in stoichiometry in reducing or oxidizing atmospheres.

\section{Experimental}

The preparation of the electrodes is performed using pulsed laser deposition (PLD), using a Coherent Compex 205 excimer laser (pulse energy up to $600 \mathrm{~mJ}$, wave length $248 \mathrm{~nm}$ ). In contrast to other deposition methods, layers prepared using pulsed laser deposition show commonly negligible shifts in cation stoichiometry from target to substrate, making it suitable for metals as well as for compounds like oxides or even more complex ceramic materials like LSM. The deposition is performed in a high-vacuum chamber at about $10^{-6}$ mbar. To enable the preparation of multilayer structures, the targets are mounted on a carousel with up to 6 different target materials.

LSM targets are manufactured by pressing the powder to small discs and subsequently sintering at 1100 ${ }^{\circ} \mathrm{C}$ for 6 hours. Beside the pure LSM layer, a codeposited layer of LSM and platinum was prepared using a segmented PLD target (volume ration LSM:platinum 1:1). Both films showed a very good adhesion on the langasite substrate.

As substrates, polished langasite plates $(0.5 \mathrm{~cm} \times 1 \mathrm{~cm})$ are used to test different electrode materials. For electrical measurements, the substrates are coated with high-temperature stable platinum contact pads using screen-printing. The samples are mounted in an alumina sample holder into a high-temperature furnace, permitting electrical measurements up to temperatures of $1450{ }^{\circ} \mathrm{C}$. Measurements are performed with a Keithley 1000 multimeter using a four terminal setup to eliminate the wire resistance. The approach permits a simple determination of the film resistance

In order to obtain comparable results for all materials, a defined temperature ramp is used for each sample. The first step is an annealing run at $500^{\circ} \mathrm{C}$ for 12 hours. Subsequently, the temperature is increased in steps of $100 \mathrm{~K}$ up to a maximum temperature of $1100{ }^{\circ} \mathrm{C}$. After each step, a dwell time of 6 hours is inserted to test the stability of the electrodes at these temperatures. Stability is assumed, if the degradation of the measured resistance is less than $1 \%$ at a constant temperature for 5 hours.

\section{Results}

\section{Platinum-based Electrodes}

Different platinum based electrodes are prepared and tested with respect to their high-temperature stability. A standard electrode with $10 \mathrm{~nm} \mathrm{Ti}$ as adhesion layer and $100 \mathrm{~nm} \mathrm{Pt}$ is defined and compared to other layer sequences with larger thickness of the Pt-film $(10 \mathrm{~nm} \mathrm{Ti}+200 \mathrm{~nm} \mathrm{Pt})$ or with $\mathrm{Al}_{2} \mathrm{O}_{3}$ protection layers. The temperature and time dependent resistance of the platinum based films is shown in Fig. 1.

The Ti/Pt electrode (used as reference in the following) shows a stable resistance with no visible degradation up to temperatures of $800{ }^{\circ} \mathrm{C}$. At $900{ }^{\circ} \mathrm{C}$ a fast degradation of the layer can be observed with its total destruction at $1000^{\circ} \mathrm{C}$. By applying a $20 \mathrm{~nm}$ alumina protection layer on the $100 \mathrm{~nm} \mathrm{Ti} / \mathrm{Pt}$ electrode, stability over at least 6 hours at $900{ }^{\circ} \mathrm{C}$ can be achieved.

The high temperature stability of platinum-based electrodes can be increased by forming an alloy with rhodium. On the one hand, this will lead to a higher melting point compared to pure platinum electrodes. On the other hand, small amounts of rhodium can also increase the oxidation resistance for the formed 
alloy [11]. The titanium/platinum-rhodium (10\%) film with a total thickness of $100 \mathrm{~nm}$ shows a significant higher stability at temperatures of $900{ }^{\circ} \mathrm{C}$. A fast degradation is observed at temperatures of $1000^{\circ} \mathrm{C}$.

To evaluate the influence of the film thickness on the stability of the electrode, one $\mathrm{Ti}(10 \mathrm{~nm}) / \mathrm{Pt} / \mathrm{Rh}$ film with $500 \mathrm{~nm}$ total thickness are deposited. This film is stable even at temperatures above $1000{ }^{\circ} \mathrm{C}$. At temperatures of $1100{ }^{\circ} \mathrm{C}$, a shift of the electrode resistance by $10 \%$ in 50 hours is observed.

For examination of the dominating failure mechanism, polished langasite substrates are coated with Ti/Pt electrodes. Some samples are covered with protective layers of $\mathrm{Al}_{2} \mathrm{O}_{3}$ or $\mathrm{Si}$. These samples are tempered for $36 \mathrm{~h}$ at $800{ }^{\circ} \mathrm{C}, 900{ }^{\circ} \mathrm{C}$ and $1000{ }^{\circ} \mathrm{C}$, respectively. Fig. 2 shows SEM pictures of the $\mathrm{Ti} / \mathrm{Pt}$ layer after annealing. At $800^{\circ} \mathrm{C}$, a destruction on the edges of the layer is visible, whereas the surface of the electrode exhibits only slight changes. Increasing temperatures lead to a formation of the already described conglomerates and cause a loss of conductivity due to island formation. Agglomeration formation seems, therefore, to be the primary failure mechanism.

The agglomeration can be prevented or at least partially suppressed by application of a protective alumina coating. After annealing at temperatures of $800^{\circ} \mathrm{C}$, no significant change compared to the as prepared sample is visible. A degradation of the layer is visible only at temperatures at $900{ }^{\circ} \mathrm{C}$ and above. The bubble like breakup visible at the latter temperature might be caused by platinum droplets, which are formed during the PLD process. The preparation of droplet free surfaces may increase the stability of the protection layer and, therefore, lead to a higher stability of the electrode.

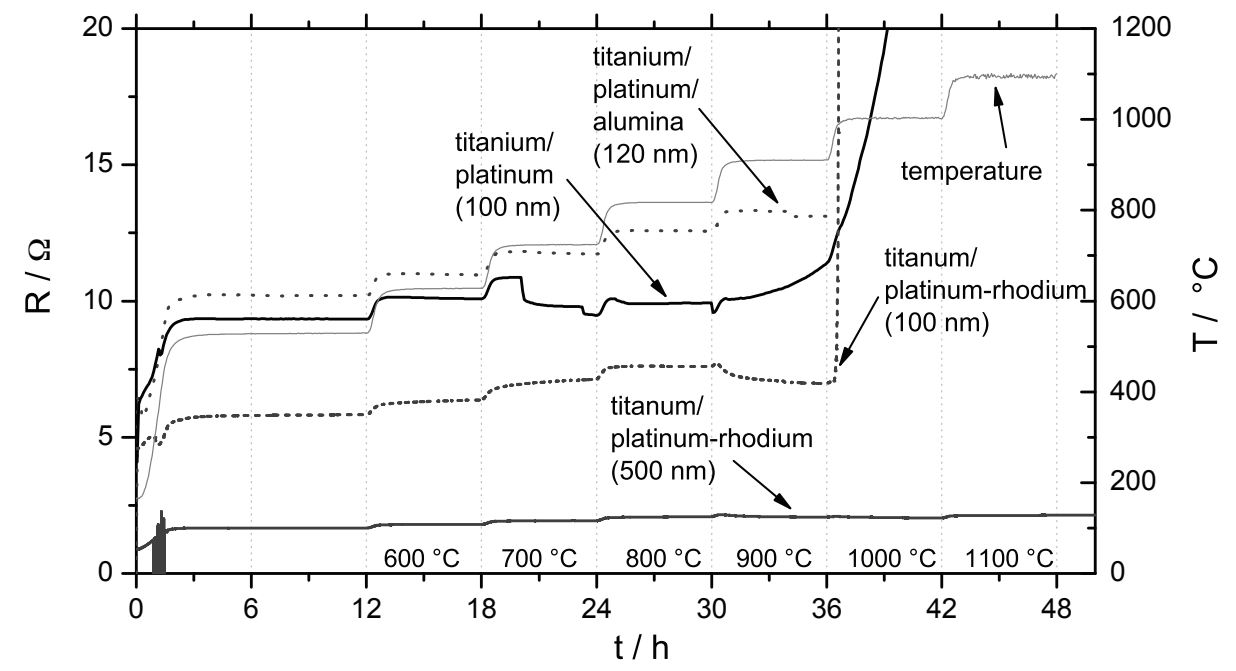

Fig. 1: Temperature and time dependent resistance of different platinum based thin films.

At temperatures of $800{ }^{\circ} \mathrm{C}$ and below, also a Si protection layer increases the stability of the layer by suppressing the agglomeration process (Fig. 2). But at temperatures of $900{ }^{\circ} \mathrm{C}$ and above, the destruction of the layer is larger than that coated by the alumina film, although there are only a few droplets visible on the electrode surface. The structures visible at temperatures of $900{ }^{\circ} \mathrm{C}$ might be platinum silicides, which are commonly formed at $\mathrm{Pt} / \mathrm{Si}$ interfaces at elevated temperatures [12,13]. The formation of silicides in thin films already takes place at temperatures of about $300{ }^{\circ} \mathrm{C}$ and exhibits an eutectic point at $830{ }^{\circ} \mathrm{C}$ explaining the destruction of the layer at temperatures of $900^{\circ} \mathrm{C}$ [14].

\section{PalladiumElectrodes}

Palladium films show a poor high-temperature stability. Even at temperatures below $600{ }^{\circ} \mathrm{C}$, a significant degradation of the layer is observed. At $800{ }^{\circ} \mathrm{C}$, there are already only insulated Pd islands visible (see Fig. 2), leading to a loss of film conductivity. The addition of an alumina protection layer $(20 \mathrm{~nm})$ does not shift the agglomeration process to significantly higher temperatures. 
$\mathrm{Ti} / \mathrm{Pt}(100 \mathrm{~nm})$ $800{ }^{\circ} \mathrm{C}$

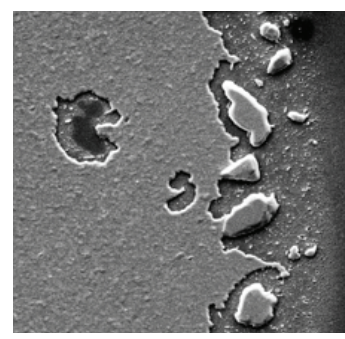

$900{ }^{\circ} \mathrm{C}$

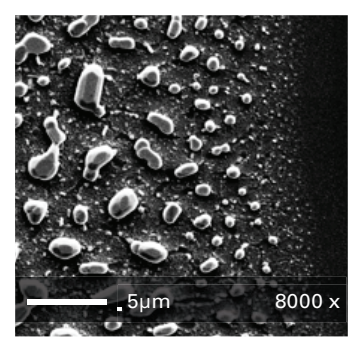

$\mathrm{Ti} / \mathrm{Pt} / \mathrm{Si}(100 \mathrm{~nm})$ $800{ }^{\circ} \mathrm{C}$

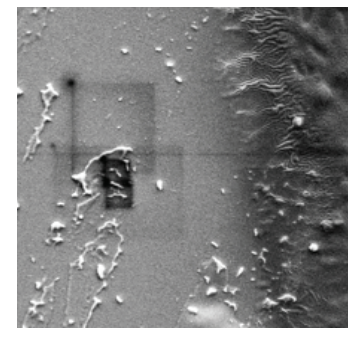

$900{ }^{\circ} \mathrm{C}$

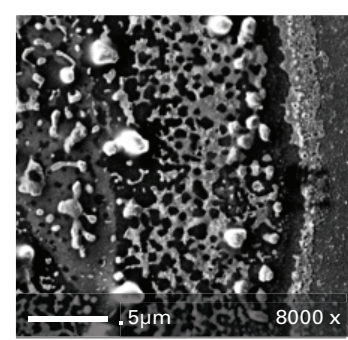

$\mathrm{Ti} / \mathrm{Pt} / \mathrm{Al}_{2} \mathrm{O}_{3}(100 \mathrm{~nm})$ $800{ }^{\circ} \mathrm{C}$

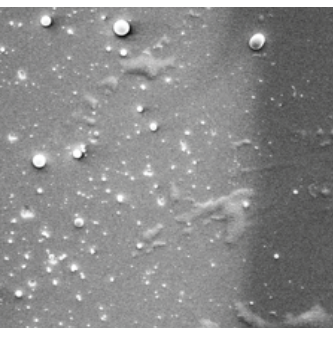

$900^{\circ} \mathrm{C}$

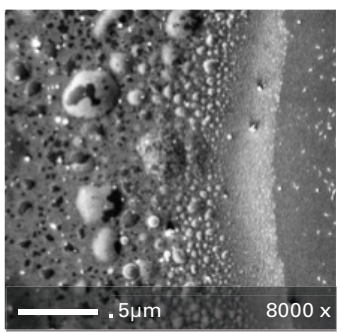

$\mathrm{Ti} / \mathrm{Pd}(\mathrm{I} 00 \mathrm{~nm})$ $800^{\circ} \mathrm{C}$

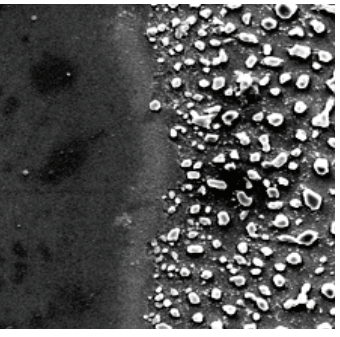

$900{ }^{\circ} \mathrm{C}$

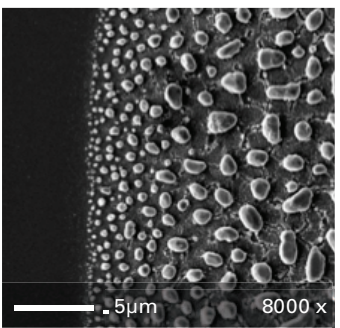

Fig. 2: SEM pictures of different metal thin films after annealing at $800^{\circ} \mathrm{C}$ and $900{ }^{\circ} \mathrm{C}$.

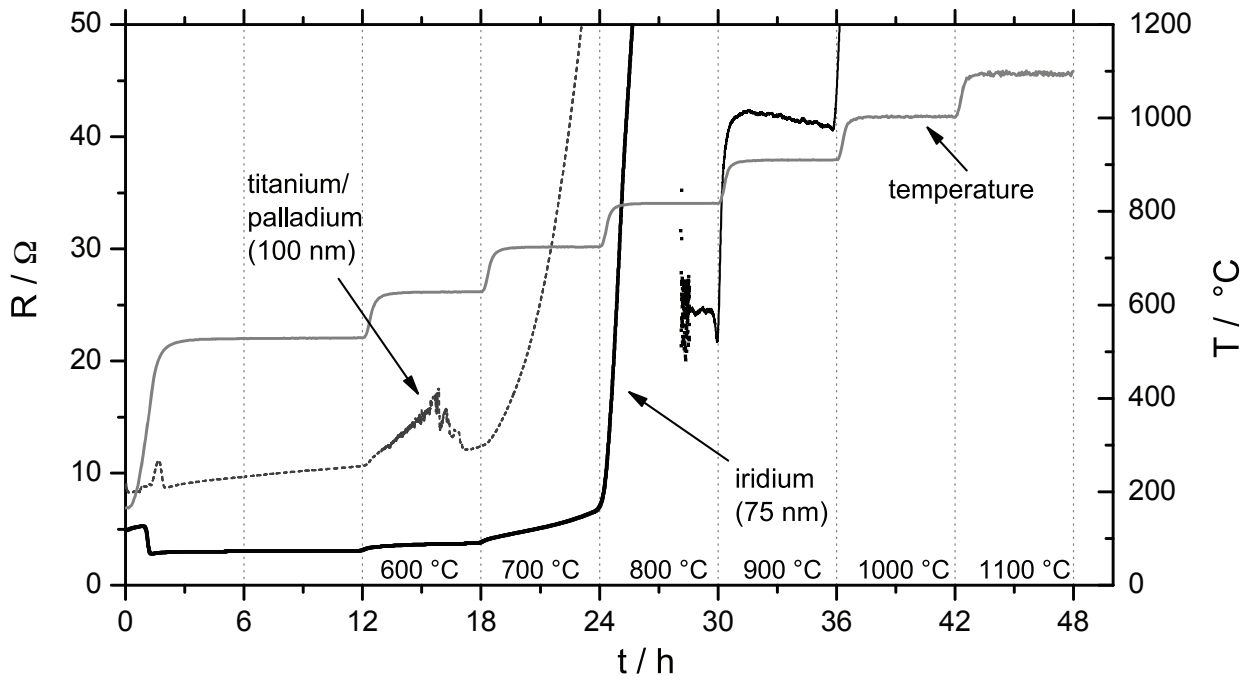

Fig. 3: Temperature and time dependent resistance of thin palladium and iridium films.

\section{Iridium Electrodes}

Iridium films with different thickness $(25 \mathrm{~nm}, 50 \mathrm{~nm}, 75 \mathrm{~nm}$ and $100 \mathrm{~nm})$ are prepared and tested at high temperatures. Films with a thickness of below $100 \mathrm{~nm}$ are found to be not stable at temperatures above $600{ }^{\circ} \mathrm{C}$. Films with a thickness of $100 \mathrm{~nm}$ show a stable resistance up to temperatures of $600{ }^{\circ} \mathrm{C}$. At 700 ${ }^{\circ} \mathrm{C}$, a significant degradation is visible followed by a total destruction of the layer at $800{ }^{\circ} \mathrm{C}$.

After an annealing at temperatures of $800^{\circ} \mathrm{C}$, the Ir film with $75 \mathrm{~nm}$ thickness shows a resistance around one order of magnitude larger than at in the lower temperature range. An explanation for this behaviour is the formation of a conductive iridium oxide layer [15] at elevated temperatures. $\mathrm{The}^{\mathrm{IrO}} \mathrm{O}_{2}$ formed at temperatures between $600{ }^{\circ} \mathrm{C}$ and $1000{ }^{\circ} \mathrm{C}$ is not volatile $[16,17]$. Since the thickness of an iridium oxide layer formed on iridium surfaces at elevated temperatures is in the range of several hundred nanometres [11], a total oxidation of the electrode is taking place. Chalamala et al. observed an on-going oxidation of iridium thin films (thickness $150 \mathrm{~nm}$ ) already at temperatures above $600{ }^{\circ} \mathrm{C}$ with a full oxidation of these films at $900{ }^{\circ} \mathrm{C}$ in less than one hour [18]. At temperatures around $1000{ }^{\circ} \mathrm{C}$, volatile $\mathrm{IrO}_{3}$ is formed and leads to an evaporation of the electrode material, which is in accordance with the observed degradation of the Ir layer $(75 \mathrm{~nm})$ at $1000^{\circ} \mathrm{C}$ shown in Fig. 3 . 
Compared to the tested platinum based films, iridium shows a good adhesion on the substrate even without an additional adhesion layer. A possible explanation is the yield strength of iridium, which is much higher than that of other noble metals [19]. While the yield strength for platinum at $750{ }^{\circ} \mathrm{C}$ is only about 20 $\mathrm{MPa}$, iridium shows a yield strength of about $140 \mathrm{MPa}$ at this temperature. Because the stress on the iridium layer in more in the elastic region, this might lead to an increased stability.

\section{Ceramic Electrodes}

In order to test ceramic electrodes, LSM $\left(\mathrm{La}_{0.65} \mathrm{Sr}_{0.35} \mathrm{MnO}_{3}\right)$ is chosen due to its high conductivity in a large temperature and oxygen partial pressure range. At temperatures of $600{ }^{\circ} \mathrm{C}$ and above, LSM electrodes with $200 \mathrm{~nm}$ thickness shows a resistance, which is only by a factor of 5 to 10 larger than that of the metal films. Up to temperatures of $900{ }^{\circ} \mathrm{C}$, a stable resistance at constant temperatures is measured. At 1000 ${ }^{\circ} \mathrm{C}$, a significant increase in resistance is observed. Fig. 4 (right) shows a SEM picture of the tested film after its failure. The formation of a polycrystalline structure with some large crystallites of up to $2.5 \mu \mathrm{m}$ in size is visible.
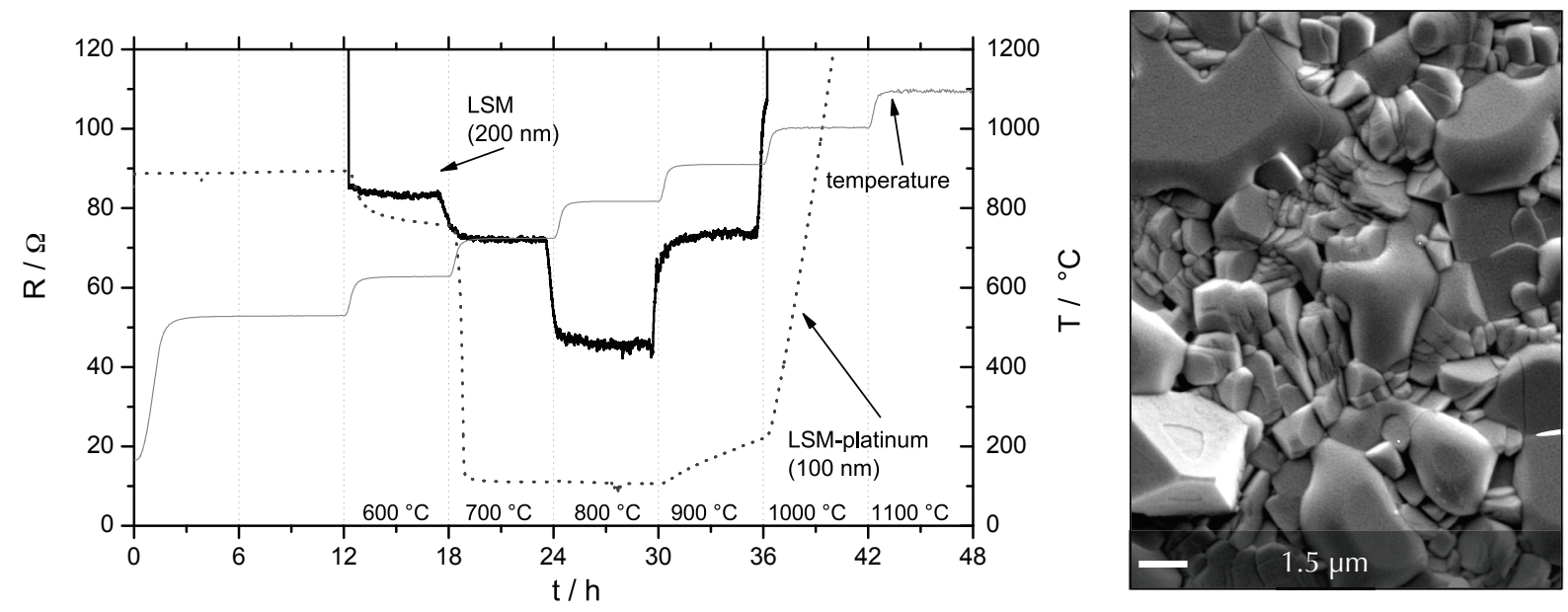

Fig. 4: Temperature and time dependent resistance of LSM and LSM-platinum thin films (left) and SEM picture of a LSM thin film $(200 \mathrm{~nm})$ after annealing at temperatures of $1000{ }^{\circ} \mathrm{C}$ for 6 hours.

The thickness of the LSM/Pt film is $100 \mathrm{~nm}$. Compared to pure LSM electrodes, a low resistance is observed at temperatures below $600{ }^{\circ} \mathrm{C}$. At temperatures of $700{ }^{\circ} \mathrm{C}$, the resistance is comparable to values obtained with pure metal electrodes. First degradation effects are visible at temperatures of $900{ }^{\circ} \mathrm{C}$. A further optimisation of this material combination should deliver higher stability and lower resistances.

\section{Summary and Conclusions}

The high-temperature stability of metal and ceramic thin films for langasite based surface acoustic wave devices is tested. Among the metal based films, Pt/Rh (10\%) exhibits the best high-temperature stability for a given film thickness. A stability of the film is observed up to temperatures of $900{ }^{\circ} \mathrm{C}$. Common $\mathrm{Ti} / \mathrm{Pt}$ films are stable up to temperatures of $700{ }^{\circ} \mathrm{C}$. A stability in the range of hours is given up to $800{ }^{\circ} \mathrm{C}$ and is therefore suitable for short-term operation.

The degradation process of the platinum based films is predominantly caused by agglomeration. This process can be significantly shifted to higher temperatures by deposition of an additional alumina protection layer. Another possibility to suppress the agglomeration is the increase of the film thickness. The highest tolerable film thickness with respect to SAW operation should be used to improve the stability of the electrodes. Palladium films show only a poor stability and should therefore not be considered as electrode material. Measurements with iridium thin films showed a degradation at temperatures of $700{ }^{\circ} \mathrm{C}$, which is dominated by the oxidation of the material.

Promising results are obtained for thin LSM films. These films are stable up to temperatures of $900{ }^{\circ} \mathrm{C}$ and showed a good conductivity in the temperature range from $600{ }^{\circ} \mathrm{C}$ to $900{ }^{\circ} \mathrm{C}$. Further improvement of the comparably low conductivity can be achieved by performing a simultaneous of LSM with platinum. The long-term stability of thin films with lateral structure sizes in the micrometre range, which will be tested in the near future, is supposed to be smaller, since agglomeration effects are expected to have a large influence on functionality such small structures.

\section{Acknowledgements}


This work was performed within the SAWHOT project, a corporate project of European and Russian universities and industrial partners. The research leading to these results has received funding from the European Community's Seventh Framework Programme ([FP7/2007-2013]) under grant agreement $\mathrm{n}^{\circ}$ [NMP4-SL-2009-247821].

\section{References}

[1] M. Schulz, D. Richter, and H. Fritze, "Material and resonator design dependant loss in langasite bulk acoustic wave resonators at high temperatures," in Ultrasonics Symposium (IUS), 2009 IEEE international, pp. 1676-1679, IEEE, 2010.

[2] R. Tiggelaar, R. Sanders, A. Groenland, and J. Gardeniers. Stability of thin platinum films implemented in high-temperature microdevices. Sensors and Actuators A: Physical, 152(1):3947, 2009.

[3] G. Bernhardt, C. Silvestre, N. LeCursi, S. Moulzolf, D. Frankel, and R. Lad. Performance of Zr and $\mathrm{Ti}$ adhesion layers for bonding of platinum metallization to sapphire substrates. Sensors and Actuators B: Chemical, 77(1-2):368-374, 2001.

[4] S. L. Firebaugh, K. F. Jensen, and M. A. Schmidt. Investigation of high-temperature degradation of platinum thinfilms with an in situ resistance measurement apparatus. Journal of Microelectromechanical Systems, 7(1):128-135, 1998.

[5] J. Chaston. Reactions of Oxygen with the Platinum Metals - The Oxidation of Platinum. Platinum Metals Review, 8(2):50-54, 1964.

[6] W. Maskell, N. Sammes, and B. Steele. Agglomeration of thin platinum films on a zirconia substrate. Journal of Physics D: Applied Physics, 20:99, 1987.

[7] G. Paulson and A. Friedberg. Coalescence and agglomeration of gold films. Thin Solid Films, 5(1):47-52, 1970.

[8] P. R. Gadkari, A. P. Warren, R. M. Todi, R. V. Petrova, and K. R. Coffey. Comparison of the agglomeration behavior of thin metallic films on $\mathrm{SiO}_{2}$. Journal of Vacuum Science and Technology A: Vacuum, Surfaces, and Films, 23:1152, 2005.

[9] K. Kreider and G. Gillen. High temperature materials for thin-film thermocouples on silicon wafers. Thin solid films, 376(1-2):32-37, 2000.

[10] S. Lee, C.-L. Chu, M.-J. Tsai, and J. Lee. High temperature oxidation behavior of interconnect coated with LSCF and LSM for solid oxide fuel cell by screen printing. Applied Surface Science, 256(6):1817-1824, 2010.

[11] H. Osamura and N. Abe. Development of new iridium alloy for spark plug electrodes. SAE transactions, 108(3):1063-1074, 1999.

[12] S. Das, K. Sheergar, D. Xu, and A. Naem. Thickness dependence of the properties and thermal stability of PtSi films. Thin Solid Films, 253(1-2):467-472, 1994.

[13] G. Majni, F. Panini, G. Sodo, and P. Cantoni. Lateral growth of platinum and palladium silicides on an $\mathrm{SiO}_{2}$ layer. Thin Solid Films, 125(3-4):313-320, 1985.

[14] G. Ottaviani. Metallurgical aspects of the formation of silicides. Thin Solid Films, 140(1):3-22, 1986.

[15] M. A. El Khakani, M. Chaker, and E. Gat. Pulsed laser deposition of highly conductive iridium oxide thin films. Applied Physics Letters, 69:2027, 1996.

[16] J. Chaston. Reactions of Oxygen with the Platinum Metals - Oxidation of Ruthenium, Rhodium, Iridium and Osmium. Platinum Metals Review, 9(2):51-56, 1965.

[17] G. Bayer and $\mathrm{H}$. Wiedemann. Formation, dissociation and expansion behavior of platinum group metal oxides ( $\left.\mathrm{PdO}, \mathrm{RuO}_{2}, \mathrm{IrO}_{2}\right)$. Thermochimica Acta, 11(1):79-88, 1975.

[18] B. Chalamala, Y. Wei, R. Reuss, S. Aggarwal, B. Gnade, R. Ramesh, J. Bernhard, E. Sosa, and D. Golden. Effect of growth conditions on surface morphology and photoelectric work function characteristics of iridium oxide thin films. Applied Physics Letters, 74:1394, 1999.

[19] Platinum Group Metals Database http://www.platinummetalsreview.com/jmpgm/ 